\title{
Redefining Caregiving as an Imperative for Supporting Caregivers: Challenges and Opportunities
}

\author{
Minakshi Raj, $P h D^{7}$ and Phillip M. Singer, $P h D^{2}$ \\ 'Department of Kinesiology and Community Health, University of Illinois at Urbana Champaign, Champaign, IL, USA; ${ }^{2}$ Department of Political \\ Science, University of Utah, Salt Lake City, UT, USA.
}

$\mathrm{J}$ Gen Intern Med 36(12):3844-6

DOI: $10.1007 / \mathrm{s} 11606-021-06932-0$

(c) Society of General Internal Medicine 2021

$\mathrm{T}$ he US health care system relies on family caregivers. More than 40 million adults provide unpaid support to a relative age 50 or older, which does not account for youth who provide caregiving. ${ }^{1}$ COVID-19 has aggravated deficiencies within caregiving policy and highlights the need to integrate family caregiving into the broader healthcare system. Not only have those infected by COVID-19 required caregiving, but the pandemic has made caregiving more difficult.

These caregiving challenges will not disappear when COVID-19 does. The Biden administration has proposed spending nearly $\$ 800$ billion to support caregivers-with $\$ 400$ billion to support home and community-based caregiving as well as enhanced benefits and protections for caregivers of adults. Though essential to infrastructure, too often caregiving is invisible. ${ }^{2}$ Nearly two-thirds of family caregivers are employed; most work full-time, and more than a quarter provide over 20 hours a week on unpaid caregiving responsibilities. ${ }^{3}$ Yet, financial support, while needed, merely puts a band-aid on a wound that requires more attention. Success in integrating family caregiving in the healthcare system through training, coordination efforts with others in the healthcare system, and compensation for their efforts, requires a fundamental redefining of what family caregiving means.

The failures of current caregiving policy are shaped by many factors. Here, we highlight how federal policy applies a narrow, one-size-fits-all approach to supporting states, caregivers and patients, and devolves authority to the states, resulting in a patchwork of uncoordinated programs and benefits that harm caregiving.

Received February 22, 2021

Accepted May 11, 2021

Published online May 28, 2021

\section{NARROWING OF FEDERAL POLICY}

The current policy to support caregivers includes the RAISE Family Caregivers Act, the Supporting Grandparents Raising Grandchildren Act, the Caregiver Advise, Record, Enable Act, the Family and Medical Leave Act (FMLA), and Medicaid. These policies define who is a caregiver, the scope of their responsibilities, and how to support them. FMLA is foundational in structuring and providing benefits for over half of the USA's workforce. Yet, these policies can impair the functioning of caregivers and limit the support available to them. FMLA enables eligible employees of covered employers to take unpaid leave for family and personal medical reasons without risking job loss. However, it limits who is defined as a caregiver and what activities are considered "caregiving" (an employee supporting a "child, spouse, or parent with a serious health condition") while ignoring others who often require caregiving, including in-law(s), siblings, or grandparents with conditions or activities that may not require medical supervision but still require other forms of support. The application of FMLA is also marked by disparities, with low-wage employees more likely to work for employers not covered by FMLA, and a majority of lower-education caregivers are less likely to access paid leave resources. ${ }^{4}$

In 2015, the Department of Labor extended employment protections to direct formal care workers providing home care services, after being excluded for decades. Yet these regulations are rife with loopholes based on caregiving duties and qualifications, limited oversight, and completely ignore informal caregiving.

Our current, narrow, policy and regulatory environment also focuses too much on the disease or disability of the person receiving care and too little on the circumstances of caregiving. ${ }^{1}$ As demonstrated during COVID-19, caregiving does not stopp at borders. ${ }^{5}$ Caregiving occurs remotely and internationally, which current policy does little to account for. Nor do current federal policies reflect the needs of special types of caregivers - including young, older, minority, sandwich generation, and rural caregivers. Each of these different types of caregivers need different policy supports. For instance, caregivers with limited English proficiency may require resources for navigating complex systems that are typically delivered in a limited number of languages. 


\section{PATCHWORK OF UNCOORDINATED PROGRAMS}

While federal policy has unnecessarily narrowed family caregiving policy, it has also delegated much of the policy responsibility to the states, resulting in a patchwork of uncoordinated programs. As the use of technology expands the opportunity for caregiving beyond proximity, the combination of uncoordinated programs and mismatched benefits can inhibit caregiving. Where you live - not your needs-determines the caregiver programs and benefits available to you. For example, states under FMLA are allowed to expand their definitions of "family member" and "serious medical condition" but there is no consistency of benefits and services across the country. Only thirteen states and the District of Columbia have adopted legislation expanding their definition of caregiving beyond FMLA and only four of them include payment for caregiving (Table 1). New York state has one of the most inclusive paid family leave policies for employees of private and public employers. Their policy covers caregivers of a child, spouse, parent/parent-in-law, grandparent, stepparent, or individuals with an in loco parentis relationship. ${ }^{6}$

Medicaid, which has a slightly broader definition of caregiving (family members, friends, or neighbors who provide unpaid assistance to a person with a chronic illness or disabling condition), similarly varies substantially. As the largest provider of caregiving services through its long-term services and supports benefits, it is a valuable program to leverage the improvement of caregiving. Medicaid has a standard set of benefits that it offers including home health services that support the enrollee and their caregiver and enrollees can use Medicaid funding to pay a family caregiver. ${ }^{7}$ States can amend these benefits, either through waivers or state plans. However, these benefits are not universal. For example, only twenty-four states use waivers to provide education, training, and counseling to family caregivers as part of their Medicaid benefits.

\section{POLICIES FOR THE FUTURE OF CAREGIVING}

Caregiving is complex and there is much to be done in redefining and strengthening caregiving policy. Caregiving policy requires significant modification at the state and federal level to be inclusive of different caregiving situations. In redefining caregiving, we must stop distinguishing caregiving and parenting in a way that excludes caregivers of adult relatives from the resources and support they need. In addition to nationalizing paid leave programs for caregivers, the Biden administration can expand family leave regulations to make existing policy more inclusive of different family and caregiving structures and of the nature of support provided and make leave more accessible to employers, administrators, and employees. For instance, financial incentives can support integrating informal caregivers into formal care. This could include increased payments if an informal caregiver is involved in telehealth visits and evaluating family caregivers for distress that could be mitigated with information about their care recipient's conditions and needs. States can leverage the flexibility they have been given to target policies that fit the needs of the caregivers in their state, while also ensuring greater access to leave policies and maintaining consistency in basic offerings. Finally, the complexity of navigating siloed health, social services, and other programs within states adds hurdles to caregivers to support their relatives and themselves. Policymakers should focus on aligning financial incentives which integrate caregiving across different policies through multi-agency solutions.

Table 1 State Expansions of FMLA*

\begin{tabular}{|c|c|c|}
\hline State: & Paid/unpaid & Care recipients recieved \\
\hline California & Unpaid & $\begin{array}{l}\text { Child, spouse, parent, domestic partner, child of domestic partner, stepparent, grandparent, grandchild, sibling, } \\
\text { or parent-in-law. }\end{array}$ \\
\hline California & Paid & Child, spouse, parent or registered domestic partner. \\
\hline Connecticut & Unpaid & Child, spouse, parent, civil union partner, parent-in-law or stepparent. \\
\hline D.C. & Unpaid & $\begin{array}{l}\text { All relatives by blood, legal custody, or marriage, } \\
\text { and anyone with whom an employee lives and has a committed relationship. }\end{array}$ \\
\hline Hawaii & Unpaid & Child, spouse, parent, in-laws, grandparents, grandparents-in-law, stepparent or reciprocal beneficiary. \\
\hline Maine & Unpaid & $\begin{array}{l}\text { Child, spouse, parent, sibling who lives with employee, civil union partner, child of civil union partner, } \\
\text { or non-dependent adult child. }\end{array}$ \\
\hline Massachusetts & Unpaid & N/A \\
\hline Minnesota & Unpaid & Child, spouse, parent, grandparent or sibling \\
\hline New Jersey & Unpaid & Child, spouse, parent, in-laws or domestic partner. \\
\hline New Jersey & Paid & Child, spouse, parent, in-laws or domestic partner. \\
\hline New York & Paid & $\begin{array}{l}\text { Child, spouse, parent, parent-in-law, step-parent, grandparent, grandchild, domestic partner, } \\
\text { or a person with whom the employee has or had an in loco parentis relationship. }\end{array}$ \\
\hline Oregon & Unpaid & $\begin{array}{l}\text { Child, spouse, parent, grandparent, grandchild or parent-in-law, } \\
\text { or a person with whom the employee has or had an in loco parentis relationship.< }\end{array}$ \\
\hline Rhode Island & Unpaid & Child, spouse, parent, employee's spouse's parents \\
\hline Rhode Island & Paid & Child, spouse, parent, employee's spouse's parents \\
\hline Vermont & Unpaid & Child, spouse, parent, employee's spouse's parents \\
\hline Washington & Unpaid & Child, spouse, parent, employee's spouse's parents \\
\hline Wisconsin & Unpaid & Child, spouse, parent, employee's spouse's parents \\
\hline
\end{tabular}

*Table adapted from the National Conference of State Legislatures 
Redefining caregiving policy requires reframing what it means to be a caregiver. Not only should policy mitigate caregiving burden but also promote and support the positive aspects of caregiving, including enabling caregivers to spend time with a relative rather than having to navigate programs. Redefining and strengthening the spectrum of caregiving is imperative to improve our health care system and the lives of those who give and receive care.

Corresponding Author: Minakshi Raj, PhD; Department of Kinesiology and Community Health, University of Illinois at Urbana Champaign, Champaign, IL, USA

\section{Declarations:}

Conflict of Interest: The authors have no conflicts of interest.

\section{REFERENCES}

1. AARP, National Alliance on Caregiving. Caregiving in the United States 2020.; 2020. https://www.aarp.org/content/dam/aarp/ppi/2020/05/ full-report-caregiving-in-the-united-states.doi. 10.26419-2Fppi.00103. 001.pdf

2. Detrow S, Gringlas S. U.S. Faces "A Child Care Emergency," Biden Says In Unveiling \$775 Billion Plan. NPR. https://www.npr.org/2020/07/21/ 893446328/new-biden-plan-would-spend-nearly-800-billion-on-caregiving. Published July 21, 2020.

3. Feinberg LF. The Dual Pressures of Family Caregiving and Employment; 2016. https://www.aarp.org/content/dam/aarp/ppi/2016-03/The-DualPressures-off-Family-Caregiving-and-Employment.pdf

4. Chen M. The Growing Costs and Burden of Family Caregiving of Older Adults: A Review of Paid Sick Leave and Family Leave Policies. Gerontologist. 2016;56(3):391-396.

5. Kent EE, Ornstein KA, Dionne-Odom JN. The Family Caregiving Crisis Meets an Actual Pandemic. J Pain Symptom Manage. 2020;60(1):66-69.

6. National Conference of State Legislatures. State Family Medical Leave Laws. National Conference of State Legislatures.

7. Kaye N, Teshale S. Medicaid Supports for Family Caregivers. National Academy for State Health Policy. Published 2020. Accessed December 22, 2020. https://www.nashp.org/medicaid-supports-for-family-caregivers/ \#toggle-id-8

Publisher's Note: Springer Nature remains neutral with regard to jurisdictional claims in published maps and institutional affiliations. 